\title{
Kebijakan Penetapan Tarif Seksio Sesarea Tanpa Penyulit dengan Metode Activity Based Costing Berdasarkan ICD-9CM pada Jaminan Kesehatan Nasional di Rumah Sakit XY Kabupaten Kudus Tahun 2016
}

\section{Tariff Determinan Policy for Sectio Caesarea without Complications using Activity-Based Cost- ing based on ICD-9CM in Jaminan Kesehatan Nasional in XY Hospital, Kudus Regency, 2016}

\author{
Amirati Dwishinta W Widjayanto', Sudiro², Chriswardani Suryawati² \\ ${ }^{1}$ Dinas Kesehatan Kabupaten Kudus \\ ${ }^{2}$ Program Magister Ilmu Kesehatan Masyarakat, Fakultas Kesehatan Masyarakat, Universitas Diponegoro, Semarang
}

Korespondensi: Amirati Dwishinta W Widjayanto,

e-mail: amirati.widjajanto@gmail.com

\begin{abstract}
Abstrak
Tarif Sectio Caesarea (SC) dalam program JKN jauh berbeda dengan tarif di Rumah Sakit. Sehingga perlu dilakukan penelitian tentang kebijakan penetapan tarif seksio sesarea tanpa penyulit dengan metode activity based costing (ABC) berdasarkan ICD9cm dalam program JKN di RS XY Kabupaten Kudus. Studi kasus ini menggunakan pendekatan kuantitatif yang didukung data kualitatif dan terbagi tiga tahap : 1). Brainstorming dan Focus Group Discussion (FGD) untuk penyusunan Clinical Pathway (CP) SC Tanpa Penyulit dan 2). Implementasi CP dan penghitungan unit cost SC Tanpa Penyulit dengan Activity Based Costing serta 3). FGD untuk merumuskan masukan kepada rumah sakit dalam menghadapi program JKN. Penelitian menghasilkan CP SC Tanpa Penyulit dan CP Penanganan Bayi Baru Lahir Sehat melalui SC Tanpa Penyulit. Hasil penghitungan unit cost SC Tanpa Penyulit kelas II Rp 5.320.957 dan kelas I Rp 5.484.564. Bila ditambahkan jasa pelayanan maka biaya yang dikeluarkan RS untuk SC Tanpa Penyulit kelas II menjadi Rp 7.485.745 dan kelas I menjadi Rp 8.380.564. Angka ini masih di atas standar tarif JKN yaitu Rp 5.306.800 (kelas II) dan Rp 6.191.300 (kelas I). Kebijakan penetapan tarif RS hanya mempertimbangkan tarif rumah sakit kompetitor. Perhitungan biaya satuan belum memasukkan biaya gedung. Dalam menghadapi program JKN, rumah sakit akan meninjau kembali struktur tarif, meningkatkan fungsi Tim Kendali Mutu dan Kendali Biaya (TKMKB), serta mengupayakan CoB (Coordination of Benefit) sebagai peluang income generating. Disarankan agar RS segera menerbitkan pedoman CP, meninjau ulang tarif dengan memasukkan biaya gedung, mencari inovasi layanan selain CoB, peningkatan peran Tim Kendali Mutu dan Kendali Biaya (TKMKB) serta mengupayakan SDM RS sadar biaya dalam rangka kendali biaya.

Kata kunci : Tarif seksio caesaria, unit cost layanan rumah sakit, Jaminan Kesehatan Nasional
\end{abstract}

\begin{abstract}
Tariff of the Caesarean Section (CS) in JKN Program is much different with the CS tariff applicable in hospital. Therefore it needs to be done the research of tariff assignment policy of CS without complications with the method of Activity-Based Costing (ABC) based on ICD-9CM in the implementation of JKN Program in XY hospital Kudus.This is an analytical case studies which has three stages. First, the preparation of Clinical Pathway (CP) CS without complications with a descriptive qualitative approach and methods of FGD and Brainstorming in data collection. Second, the implementation of CP and the calculation of unit cost of the CS without complications with the quantitative approach and methods of observation ctivity Based Costing. Third, analysis of the results and follow-up of the internal hospital policy to face JKN program by qualitative approach and FGD method. Research results generate CP CS without complication adn CP handling New Healthy Baby Born through CS without Complication. The calculation results of the CS without complications unit cost class II is Rp5,320,957 and Rp5,484,564 for class I. When added with the services then cost of CS without complications class II become Rp7,485,745. and Rp8,380,564 for class I. This figureis still above the applicable standard price of JKN which Rp5.306.800 for class II and Rp6.191.300 for class I. All this time, the hospital policy on tariff setting the priority component competitors as a consideration factor.

Key words: Tariff of the Caesarean Section, Hospital Care Unit Cost, Universal Health Coverage
\end{abstract}

\section{Pendahuluan}

Program Jaminan Kesehatan Nasional (JKN) diberlakukan di Indonesia sejak 1 Januari 2014. Badan Penyelenggara Jaminan Sosial (BPJS) Kesehatan selaku badan hukum penyelenggara program JKN wajib membayar pelayanan kesehatan pesertanya kepada fasilitas kesehatan baik Fasilitas Kesehatan Tingkat Pertama (FKTP) dan Fasilitas Kesehatan
Rujukan Tingkat Lanjut (FKRTL). Pembayaran biaya pelayanan rumah sakit dilakukan dengan model case-mix Indonesian Case Base Groups (INA-CBGs) yang ditetapkan berdasarkan peraturan Menteri Kesehatan.

Tarif INA CBGs untuk pelayanan dengan tindakan seperti obstetri ginekologi rata-rata lebih rendah dibandingkan dengan tarif riil rumah sakit. Dengan 
diberlakukannya paket tarif INA CBGs ini mengharuskan manajer rumah sakit melakukan subsidi silang antara tarif INA CBGs non tindakan terhadap tarif INA CBGs dengan tindakan. Kenyataannya subsidi silang ini sulit dilakukan pada rumah sakit dengan jumlah layanan tindakan yang tinggi.

Kondisi di atas dialami pula oleh Rumah Sakit XY di Kabupaten Kudus sebagai rumah sakit provider program JKN. Kendala terberat penyesuaian tarif yang berlaku bagi klaim pasien JKN khususnya untuk tindakan operatif. Selisih antara tarif Secsio Caesarea (SC) tanpa penyulit RS dengan tarif INA CBGs SC ringan berkisar antara Rp. 3.843.500,sampai dengan $\mathrm{Rp}$ 4.112.200,-. Dalam dua tahun terakhir ini angka tindakan SC mencapai 33,54\% dari seluruh tindakan terminasi kehamilan di rumah sakit tersebut dan dari $60,89 \%$ tindakan operatif yang ada maka SC menduduki tindakan operatif terbanyak. SC pada peserta BPJS mencapai 24,38\% dari total SC yang ada. SC mempergunakan sumber daya yang besar yaitu tenaga medis, paramedis, kamar operasi beserta alat medisnya serta obat dan bahan habis pakai

Rumah Sakit XY belum pernah menghitung unit cost yang didasarkan pada clinical pathway (CP) sebagai dasar penetapan tarif yang diberlakukan. Bila hal tersebut dilakukan maka variasi pemeriksaan, tindakan dan penggunaan sumber daya dapat ditekan sehingga upaya untuk kendali mutu dan kendali biaya pada tindakan SC di Rumah Sakit XY dapat diperoleh hasilnya. Untuk kepentingan tersebut maka diperlukan penelitian tentang kebijakan penetapan tarif Seksio Cesarea Tanpa Penyulit di RS XY dalam kaitannya dengan program JKN.

\section{Metodologi Penelitian}

Penelitian ini dirancang dalam empat tahap yaitu: 1). Penyusunan CP SC Tanpa Penyulit, 2). Implementasi CP yang telah tersusun pada tahap pertama dan 3). penghitungan unit cost SC Tanpa Penyulit, serta 4). Analisis hasil dan tindak lanjut kebijakan internal rumah sakit XY dalam menghadapi program JKN.

Jenis penelitian ini adalah penelitian studi kasus analitik dengan penerapan metode SC Tanpa penyulit di Rumah Sakit XY Kabupaten Kudus dengan pendekatan deskriptif kuantitatif dan didukung data kualitatif. Proses pengumpulan data ada beberapa tahap yaitu :1). Penyusunan clinical pathway SC Tanpa penyulit dilakukan dengan metode Delphi dan FGD kepada dokter obsgyn dan manajer rumah sakit dengan berdasarkan beberapa pedoman. Karena pada tahap penyusunan CP ditemukan kendala dalam metode Delphi. Beberapa dokter spesialis obsgyn sulit ditemui dan kurang memahami CP, bahkan keberatan terlibat dalam penyusunan $\mathrm{CP}$ dan kemudian dilakukan perubahanmetode dengan cara brainstorming sehingga dapat menggali jawaban responden. 2). Implementasi CP dilakukan dengan observasi terhadap beberapa tindakan SC tanpa penyulit. 3). Penghitungan unit cost dengan metode $\mathrm{ABC}$ dengan mengisi form pengumpulan data biaya dan data-data pendukung lainnya. 4). FGD untuk merancang tindak lanjut rumah sakit berdasar hasil implementasi CP dan penghitungan unit cost SC Tanpa penyulit.

\section{Hasil Penelitian}

RS XY Kabupaten Kudus merupakan rumah sakit swasta kelas D dengan brand image layanan Obstetri dan Ginekologi. Rumah sakit XY dilengkapi dengan layanan Instalasi gawat darurat (IGD) pada Pelayanan Obstetri Neonatal Emergensi Komprehensif (PONEK), delapan buah tempat tidur di ruang bersalin dan tiga buah tempat tidur di ruang bersalin VIP. Rumah sakit XY memiliki 4 orang dokter spesialis kebidanan dan kandungan (obsgyn), 2 orang dokter spesialis anak dan 2 orang dokter spesiaslis anestesi. Rumah Sakit XY telah bergabung dalam program Jamkesmas dan Jampersal dan sejak 2014 bergabung dalam JKN. ${ }^{6}$

\section{Penyusunan Clinical pathway (CP) Secsio Caesarea Tanpa Penyulit}

Penyusunan draft Clinical Pathways SC Tanpa Penyulit dengan FGD dan melibatkan direksi dan petugas di unit pelayanan terkait. Penjelasan tentang CP dilakukan terlebih dahulu karena sebagian besar peserta FGD belum memahami CP. Selain itu juga dilakukan upaya menyamakan persepsi tentang definisi operasional dari SC Tanpa Penyulit dan kasus kehamilan apa saja yang diiberi tindakan SC Tanpa Penyulit. Koreksi juga dilakukan oleh peserta diskusi berdasarkan ilmu pengetahuan terkini, Buku Acuan Nasional Pelayanan Kesehatan Maternal dan Neonatal, Buku Panduan Praktis Pelayanan Kesehatan Maternal dan Neonatal, Formularium RS XY dan Formularium Nasional. Draft CP dimulai sejak pelaksanaan Pra Operasi di IGD, operasi SC sampai pasien pulang. Muncul beberapa kesepakatan baru antara lain yaitu kesepakatan pemeriksaan $\mathrm{HbSAg}$ wajib dilakukan.

Draft CP SC Tanpa Penyulit yang telah disusun 
didiskusikan secara brainstorming untuk mendapatkan masukan dari pakar/para dokter spesialis terkait. Kendala yang muncul yaitu belum semua spesialis memahami benar tentang CP, sulitnya menemui para dokter spesialis terlebih dokter mitra serta terjadi penolakan dari dokter spesialis mitra terhadap draft CP. Pada tahap ini tiap dokter spesialis memberi masukan mengenai prosedur apa yang perlu/tidak perlu dilakukan, kapan suatu prosedur dilakukan, sumber daya apa saja yang perlu digunakan. Hasil yang didapatkan dalam tahap ini adalah dokumen CP SC Tanpa Penyulit dan CP Penanganan Bayi Baru Lahir Sehat melalui SC Tanpa Penyulit.

CP yang telah tersusun berfungsi sebagai garis pelayanan yang memberi batasan aktivitas apa saja yang terlibat dalam proses pelayanan, menetapkan sumber daya apa saja yang dikonsumsi untuk menghasilkan suatu layanan kesehatan. Proses ini juga menunjukkan perlunya kerja sama multidisipliner secara intens dan detail agar bisa menghasilkan standar pelayanan kesehatan. Hasil yang diharapkan dari penyusunan CP ini adalah mengoptimalkan pemanfaatan sumber daya namun tetap berupaya memaksimalkan kualitas pelayanan., ${ }^{7,8}$

\section{Implementasi Clinical Pathway SC Tanpa Penyulit:}

Implementasi dokumen CP SC Tanpa Penyulit dilakukan pada pasien BPJS selama dua minggu dan dilakukan oleh dokter spesialis obstetri dan ginekologi tetap dengan pertimbangan merekalah yang diharapkan nantinya dapat menjalankan CP secara konsisten. Implementasi CP selama 2 minggu karena dikhawatirkan bila terlalu lama maka akan mengganggu proses pelayanan rumah sakit. Selama dua minggu diperoleh dua orang pasien dengan diagnosis SC Tanpa Penyulit dan pasien peserta BPJS. Pasien pertama adalah pasien kelas utama dengan kepesertaan BPJS di kelas II, pasien yang lain dirawat di kelas VIP dengan kepesertaan BPJS di kelas I.
Pada saat implementasi dilakukan terdapat varian antibiotik yang digunakan, namun karena kedua kasus tersebut mengalami varian yang sama maka harga antibiotik yang digunakan dalam penghitungan unit cost adalah harga antibiotik yang disebutkan dalam varian. Hal ini menunjukkan bahwa CP mampu mengurangi variasi pelayanan dan meningkatkan homogenitas pelayanan, bila varian terjadi, maka varian tersebut dicatat untuk evaluasi CP 10,11

Implementasi CP memudahkan penelusuran aktivitas apa saja yang dilakukan di unit pelayanan dan memandu peneliti untuk menggali sumber daya yang digunakan dalam proses SC Tanpa Penyulit dan proses penanganan bayi baru lahir melalui SC Tanpa Penyulit. Langkah ini membuktikan besarnya fungsi CP dalam analisis biaya 10,12,13,14

Tahap selanjutnya adalah penghitungan unit cost dengan metode ABC. Langkah awal yang dilakukan adalah menelusuri biaya tidak langsung dari facility activity/unit penunjang dan selanjutnya menelusuri biaya tak langsung dan biaya langsung dari unit activity/unit produksi. CP berperan sebagai pemandu dalam menelusur aktivitas dan sumber daya yang digunakan pada unit activity. Nominal biaya tak langsung facility activity dibebankan kepada biaya tak langsung unit activity. Hasil dari penambahan biaya tak langsung dengan biaya langsung akan menghasilkan unit cost tiap produk pelayanan di unit activity. Hasil penghitungan unit cost dapat dilihat pada Tabel 1 .

Tabel 1 menggambarkan perbedaan unit cost terdapat pada unit produksi IGD PONEK dan Rawat Inap Nifas karena biaya untuk laboratorium dan fasilitas yang ada di ruang perawatan nifas. Perbedaan tersebut diantaranya harga bangunan ruangan kamar, harga bed pasien termasuk set sprei, sarung bantal dan laken serta ada tidaknya televisi, AC, kulkas, water heater di kamar mandi, perbedaan paket nutrisi (makanan) yang diberikan, sedang-

Tabel 1. Hasil penghitungan unit cost SC Tanpa Penyulit untuk kelas II, I, utama, dan VIP

\begin{tabular}{|c|c|c|c|c|}
\hline Kelas & II & I & Utama & VIP \\
\hline 'IGD PONEK & 481.944 & 492.144 & 492.144 & 502.854 \\
\hline VK & 563.270 & 563.270 & 563.270 & 563.270 \\
\hline OK & 1.915 .612 & 1.915 .612 & 1.915 .612 & 1.915 .612 \\
\hline Ranap Nifas & 1.556 .087 & 1.709 .493 & 2.474 .170 & 2.113 .364 \\
\hline Transit BBL & 189.012 & 189.012 & 189.012 & 189.012 \\
\hline Ranap BBL & 615.032 & 615.032 & 615.032 & 615.032 \\
\hline Jumlah & 5.320 .957 & 5.484 .564 & 6.249 .241 & 5.899 .145 \\
\hline \multicolumn{5}{|c|}{$\begin{array}{l}\text { Catatan sebagai perbandingan hasil UC: } \\
\text { 1). SC Tanpa Penyulit di RS Bayangkara Yogyakarta (tahun 2014) : Klas I Rp5.877.266 dan Klas II Rp.5.097.549. }{ }^{15} \\
\text { 2). SC Tanpa Penyulit di IBS RS. PKU Muhammadiyah Yogyakarta ( tahun 2014) Rp1.662.648. }{ }^{16}\end{array}$} \\
\hline
\end{tabular}


Tabel 2 Jasa pelayanan untuk tiap unit activity

\begin{tabular}{lcccc}
\hline \multicolumn{1}{c}{ Unit Activity } & Kelas II & Kelas I & Kelas Utama & Kelas VIP \\
\hline IGD PONEK & 57.500 & 67.500 & 90.000 & 100.000 \\
Pra OP VK & 70.000 & 92.500 & 140.000 & 170.000 \\
Ruang OP & 1.827 .000 & 2.436 .000 & 3.248 .000 & 3.654 .000 \\
Ranap Nifas & 105.000 & 150.000 & 240.000 & 300.000 \\
Transit BBL & - & - & - & - \\
Ranap BBL & 105.000 & 150.000 & 240.000 & 300.000 \\
\hline JUMLAH & 2.164 .500 & 2.896 .000 & 3.958 .000 & 4.524 .000 \\
\hline
\end{tabular}

Tabel 3 Hasil Penghitungan Unit Cost SC Tanpa Penyulit RS XY Kudus

\begin{tabular}{lccc}
\hline \multicolumn{1}{c}{ Kelas } & Unit Cost (Rp) & Jasa Pelayanan (Rp) & Jumlah (Rp) \\
\hline I & 5.320 .957 & 2.164 .500 & 7.485 .745 \\
II & 5.484 .564 & 2.896 .000 & 8.380 .564 \\
Utama & 6.249 .241 & 3.958 .000 & 10.207 .241 \\
VIP & 5.899 .145 & 4.524 .000 & 10.423 .145 \\
\hline
\end{tabular}

kan sumber daya yang digunakan di unit produksi lainnya sama untuk semua kelas. Biaya laboratorium berbeda untuk tiap kelas perawatan karena rumah sakit melakukan kerja sama operasional (KSO) dengan pihak ketiga. Biaya nutrisi menggunakan harga yang telah ditetapkan oleh RS karena keterbatasan peneliti menelusuri data yang ada di layanan gizi. Kejanggalan terjadi pada unit cost kelas utama dan VIP dimana nominal VIP malahan lebih rendah. Setelah ditelusur ternyata terdapat kekeliruan dalam menetapkan harga nutrisi perporsi untuk kelas VIP oleh manajer rumah sakit. Kondisi tersebut sangat berpengaruh pada hasil akhir penghitungan unit cost.

Setelah unit cost didapatkan, maka langkah selanjutnya menambahkan jasa pelayanan. Jasa pelayanan yang ditambahkan berdasarkan Daftar Perubahan Tarif Layanan di Rumah Sakit XY. Seperti halnya penghitungan unit cost, penghitungan jasa pelayanan dilakukan di tiap unit produksi. Hasil dari penghitungan jasa pelayanan tampak pada Tabel 2 .

Perbandingan antara unit cost dengan jasa pelayanan pada Tabel 3 menggambarkan dengan jelas bahwa jasa pelayanan memberikan kontribusi yang cukup besar terhadap besarnya tarif pelayanan SC TP. Berdasarkan hasil FGD pihak rumah sakit sulit mengintervensi pengeluaran ini karena rumah sakit membutuhkan kehadiran para dokter spesialis tersebut. Besaran jasa pelayanan yang diberikan saat ini juga didasarkan atas besarnya jasa pelayanan rumah sakit kompetitor. Hingga saat ini belum ada acuan baku sebagai dasar penetapan jasa pelayanan. Rumah Sakit sulit menurunkan besaran jasa pelayanan pasie untuk menurunkan tarif SC Tanpa Penyulit.

Di dalam penetapan tarif SC Tanpa Penyulit maka angka-angka unit cost pada Tabel 3 masih harus memperhatikan "konstanta" tertentu. Struktur tarif dibangun dari jasa sarana yang terdiri dari unit cost ditambah jasa pelayanan dan konstanta. Konstanta tersebut dipengaruhi oleh visi dan misi rumah sakit, keberadaan subsidi pemerintah (bagi rumah sakit pemerintah), ability to pay (ATP) dan willingness to pay (WTP) masyarakat, kebijakan rumah sakit pesaing dan sebagainya. Oleh karena itu hasil penghitungan tersebut perlu dibahas pada pertemuan manajer rumah sakit XY untuk menentukan konstanta apa yang akan dipertimbangkan dan berapa besarannya. ${ }^{17}$

Langkah selanjutnya dalam tahap penelitian ini adalah membandingkan hasil penambahan unit cost dan jasa pelayanan dengan rekening tagihan pasien, hasil klaim BPJS yang diterima RS, tarif INA-CBG's sesuai dengan Permenkes nomor 59 tahun 2014, 
Tabel 4. Perbandingan hasil penghitungan unit cost, rekening tagihan pasien, klaim BPJS Kesehatan dan tarif INA CBG's sesuai peraturan yang berlaku

\begin{tabular}{|c|c|c|c|c|c|}
\hline \multirow[b]{2}{*}{ Kelas Perawatan } & \multirow{2}{*}{$\begin{array}{l}\text { Penghitungan Unit Cost } \\
\text { dan Jasa Pelayanan }\end{array}$} & \multirow{2}{*}{$\begin{array}{l}\text { Rekening Tagihan } \\
\text { Pasien }\end{array}$} & \multirow{2}{*}{$\begin{array}{l}\text { Klaim BPJS } \\
\text { Kesehatan }\end{array}$} & \multicolumn{2}{|c|}{ Tarif INA CBG’s } \\
\hline & & & & $\begin{array}{l}\text { Permenkes } \\
59 / 2014\end{array}$ & $\begin{array}{c}\text { Permenkes } \\
52 / 2016 \text { dan } \\
64 / 2016\end{array}$ \\
\hline Kelas II & 7.485 .745 & - & 4.387 .800 & 4.387 .500 & 5.306 .800 \\
\hline Kelas I & 8.380 .564 & - & 5.119 .100 & 5.119 .100 & 6.191 .300 \\
\hline Kelas Utama & 10.207 .241 & 7.607.272 & - & & \\
\hline Kelas VIP & 10.423 .145 & 11.184 .447 & - & & \\
\hline
\end{tabular}

Tabel 5. Cost recovery rate dari rata-rata tagihan pasien umum dibandingkan dengan unit cost dan jasa pelayanan

\begin{tabular}{|c|c|c|c|c|c|}
\hline \multirow[b]{2}{*}{ Kelas Perawatan } & \multirow{2}{*}{$\begin{array}{l}\text { Rata-rata tagihan } \\
\text { pasien umum }\end{array}$} & \multicolumn{2}{|c|}{ Unit Cost dengan Jasa Pelayanan } & \multicolumn{2}{|c|}{$\mathrm{CRR}_{1}(\%)$} \\
\hline & & $\begin{array}{l}\text { (dengan depresiasi } \\
\text { gedung) }\end{array}$ & $\begin{array}{l}\text { (tanpa depresiasi } \\
\text { gedung) }\end{array}$ & $\begin{array}{l}\text { (dengan depresiasi } \\
\text { gedung) }\end{array}$ & $\begin{array}{l}\text { (tanpa depresiasi } \\
\text { gedung) }\end{array}$ \\
\hline Kelas II & 7.530 .748 & 7.485 .745 & 7.357.467 & 100,60 & 102,36 \\
\hline Kelas I & 8.410 .679 & 8.380 .564 & 8.235 .800 & 100,36 & 102,12 \\
\hline Kelas Utama & 7.893 .261 & 10.207 .241 & 10.035 .963 & 77,33 & 78,65 \\
\hline Kelas VIP & 11.054 .536 & 10.423 .145 & 10.265 .055 & 106,06 & 107.69 \\
\hline
\end{tabular}

Tabel 6. Cost Recovery Rate (CRR) dari Tarif INA CBGs dibandingkan dengan Unit Cost (dengan memasukkan Jasa Pelayanan)

\begin{tabular}{lccc}
\hline \multicolumn{1}{c}{ Kelas Perawatan } & Tarif INA CBGs & $\begin{array}{c}\text { Unit Cost dengan } \\
\text { Jasa Pelayanan }\end{array}$ & CRR $_{1}(\%)$ \\
\hline Permenkes no 59 th 2014 & & & 58,62 \\
Kelas II & 4.387 .800 & 7.485 .745 & 61,08 \\
Kelas I & 5.119 .100 & 8.380 .564 & 70,89 \\
Permenkes no 52 th 2016 dan Permenkes no 69 th 2016 & 5.306 .800 & 7.485 .745 & 73,88 \\
Kelas II & 6.191 .300 & 8.380 .564 & \\
Kelas I &
\end{tabular}

Permenkes nomor 52 tahun 2016 dan Permenkes nomor 64 tahun 2016. Rekening Tagihan Pasien yang dimaksud merupakan billing pada pasien yang menggunakan clinical pathway.

Perbandingan ini dilakukan untuk melihat besarnya perbedaan antara biaya yang dikeluarkan RS dalam melakukan pelayanan SC Tanpa Penyulit, iur bayar dari pasien karena naik kelas, pembayaran yang diterima dari BPJS, serta tarif INA CBG's yang berlaku saat implementasi dilakukan dan tarif INA CBG's yang berlaku saat ini. Perbandingan tersebut dapat dilihat pada Tabel 4.

Untuk melengkapi perbandingan, dilakukan perhitungan rata-rata billing pembayaran dari pasien umum di tiap kelas perawatan. Kelas III didapatkan hasil Rp.6.052.961; kelas II sebesar Rp7.530.748; kelas I Rp8.410.679; kelas utama Rp7.893.261; dan kelas VIP Rp11.054.536. Hasil penghitungan Cost 
Recovery Rate (CRR) dari rata-rata tagihan pasien umum dibandingkan dengan unit cost dan jasa pelayanan dapat dilihat pada Tabel 5

Penghitungan dilakukan dua kali mengingat dalam FGD kedua tergali informasi bahwa dalam menghitung biaya dasar untuk tarif belum dimasukkan biaya depresiasi gedung. Hasil penghitungan pada Tabel 5 menunjukkan bahwa tarif pasien umum yang selama ini berlaku mendekati hasil penghitungan unit cost bila ditambahkan dengan jasa pelayanan. Dari tabel 5 dapat diketahui bahwa keuntungan (profit) yang diambil RS sangat minimal untuk kasus dengan tindakan SC Tanpa Penyulit karena mendekati total biaya yang dikeluarkan baik unit cost (dengan jasa pelayanan) dengan atau tanpa depresiasi gedung. Jumlah nominal tagihan di kelas utama yang lebih rendah daripada kelas I perlu ditelusuri lebih lanjut diperkirakan ada kekeliruan dalam memasukkan komponen tagihan atau penetapan tarif per unit pelayanan yang kurang tepat.

Penghitungan CRR dapat pula dilakukan antara tarif INA CBGs dibandingkan dengan hasil penghitungan unit cost dan jasa pelayanan untuk tiap kelas. Penetapan besarnya jasa pelayanan RS XY dengan mempertimbangkan jasa pelayanan rumah sakit kompetitor. Hasil penghitungan dapat dilihat pada Tabel 6.

Penghitungan $\mathrm{CRR}_{1}$ menunjukkan bahwa perbandingan tarif INA CBGs berdasarkan Permenkes no 59 tahun 2014 dengan hasil penghitungan unit cost dan jasa pelayanan yang berlaku adalah $58,62 \%$ untuk perawatan kelas II dan 61,08\% untuk kelas I. Hal ini menunjukkan beban RS untuk menutup kekurangan biaya operasional berkisar 40\%. Sementara itu penghitungan $\mathrm{CRR}_{2}$ berdasarkan Permenkes no 52 tahun 2016 dan no 64 tahun 2016 menunjukkan sedikit peningkatan. Tagihan yang diterima untuk memberikan pelayanan SC Tanpa Penyulit di Kelas II yaitu 70,89\% dari unit cost dan jasa pelayanannya sementara itu untuk kelas I sebesar 73,88\%. Meskipun telah terjadi peningkatan tarif INA CBGs, namun rumah sakit XY masih memiliki beban operasional bila memberikan pelayanan SC tanpa penyulit karena masih terdapat selisih biaya yang menjadi beban rumah sakit XY sekitar 26\% sampai dengan 29\%. Manajer Rumah Sakit XY perlu mencari peluang lain untuk dapat menutup kekurangan biaya tersebut dan meningkatkan revenue dari sektor lain.

Hasil perbandingan tersebut kemudian dibahas dalam Focus Group Discussion untuk mendiskusikan hasil perhitungan tersebut dan tindak lanjut kebijakan internal RS dalam mengantisipasi program JKN. FGD dihadiri oleh 16 orang anggota Tim Tarif Rumah Sakit XY yang terdiri dari Direktur, Wakil Direktur Non Medis, Wakil Direktur Medis, Kepala Bidang Pelayanan Medis, Kepala Bidang Penunjang Medis, Kepala Bagian Keuangan, Staf Bagian keuangan, Kepala Unit VK (kamar bersalin), Satuan Pengawas Internal, Ketua Tim Mutu dan Kendali Biaya (TMKB), Verifikator Internal, Dokter IGD serta Ketua Badan Penasehat Harian RS XYW.

FGD dimulai dengan penyampaian tahap penelitian yang telah dilalui sebelumnya. Selanjutnya dilakukan diskusi mengenai cara penetapan tarif RS, faktor apa saja yang mempengaruhi penetapan tarif, bagaimana kebijakan RS dalam penetapan tarif serta bagaimana kebijakan RS dalam menghadapi program JKN. Dalam diskusi didapatkan hasil bahwa pembentukan Tim Tarif merupakan langkah awal dalam penyusunan tarif. Tim tersebut bertanggung jawab untuk mengidentifikasi masalah, menyediakan data sebagai bahan pembahasan tarif, menganalisis, dan bersama-sama menyusun tarif. Tim Tarif terdiri dari unsur direksi, kepala bagian keuangan, kepala bidang pelayanan medis, kepala bidang penunjang medis, kepala unit pelayanan, kepala unit penunjang, Satuan Pengawas Internal (SPI), serta dari BPH (Badan Pengurus Harian) selaku perwakilan pengurus yayasan. Tim melakukan rapat untuk mengevaluasi tarif yang berlaku saat ini, membahas relevan tidaknya tarif yang berlaku dengan kondisi saat ini serta perlu tidaknya dilakukan perubahan tarif. Evaluasi tarif dilakukan setahun sekali di akhir tahun.

Dari hasil diskusi didapatkan hasil bahwa komponen apa yang akan diperhitungkan dalam penetapan tarif ditentukan oleh tim tarif. Saat ini Rumah Sakit XY telah berupaya menghitung biaya dasar dengan menggunakan modifikasi dari beberapa cara dan biaya dasar inilah yang menjadi dasar penghitungan tarif. Namun biaya dasar yang dihitung ternyata belum memasukkan harga bangunan dengan pertimbangan bahwa tanah dan bangunan yang ada sebagian besar merupakan wakaf. Biaya depresiasi yang dihitung oleh bagian keuangan dianggap sebagai dana cadangan dan saat ini dana tersebut lebih banyak digunakan untuk investasi perluasan usaha seperti membangun pelayanan hemodialisa, instalasi gizi, laundry, dan parkir. Hasil diskusi mengusulkan RS XY akan menghitung lagi biaya dasar tersebut. Dalam diskusi juga disepakati bahwa tidak ada perbedaan antara jasa pelayanan pasien JKN dengan 
pasien umum dan hal tersebut dapat diterima baik oleh para dokter Rumah Sakit XY. Faktor tarif kompetitor dan ATP/WTP merupakan konstanta yang perlu diperhitungkan dalam penetapan tarif RS X. Analisis terhadap kompetitor dan ATP/WTP dilakukan dengan cara benchmarking dengan memperhatikan kondisi geografis Rumah Sakit XY. Survey yang telah dilakukan oleh Rumah Sakit XY menunjukkan bahwa tarif tindakan yang diberlakukan merupakan tarif terendah di daerah perkotaan di Jawa Tengah. Rumah Sakit XY akan membuat kebijakan untuk menghitung kembali pola pentarifan terutama untuk layanan dengan tindakan.

\section{Pembahasan}

Menyikapi perbedaan unit cost SC Tanpa Penyulit, tarif rumah sakit dan tarif BPJS Kesehatan maka kebijakan rumah sakit dalam menghadapi JKN diantaranya dengan meninjau kembali struktur tarif diantaranya dengan memberi batasan tindakan sesuai kebijakan rumah sakit dan memberi batasan sumber daya sesuai dengan yang telah ditetapkan. Efisiensi biaya rumah sakit dapat dilakukan terutama untuk obat dan bahan medis habis pakai di unit terkait. ${ }^{9}$

Manajer Rumah Sakit XY telah membentuk Tim Kendali Mutu dan Kendali Biaya (KMKB) yang berfungsi memantau kepatuhan SDM rumah sakit terhadap kebijakan rumah sakit. Manajer akan mengupayakan pertemuan Komite Medik lebih sering dilakukan agar Tim KMKB lebih mudah dalam melakukan tugasnya. Tim KMKB telah memberikan laporan tentang tindakan/perawatan apa saja yang telah dilakukan, berapa rupiah klaim BPJS Kesehatan, berapa rekening tagihan pasien dan apakah kasus tersebut menimbulkan kerugian atau keuntungan bagi RS. Dari laporan tersebut diharapkan muncul kendali biaya para dokter dan tim. Gerakan sadar biaya dan sadar mutu pelayanan dapat dilakukan secara terstruktur dengan pembentukan Komite Mutu, Komite Medis, Komite Keperawatan dan komite JKN. Kebijakan lainnya adalah melakukan $\mathrm{CoB}$ (Coordination of Benefit) dengan cara bekerja sama dengan asuransi swasta untuk pasien yang mempunyai double protection yaitu sebagai pesertaan BPJS Kesehatan dan asuransi kesehatan lainnya.

Situasi keuangan Rumah Sakit XY pada saat ini tidak dalam kondisi mengkhawatirkan bagi keberlangsungan rumah sakit. Meskipun core bussines RS layanan obstetri dan ginekologi, namun subsidi silang dari unit pelayanan lain masih sanggup menutup kesenjangan tarif tindakan terutama SC karena an- gka tindakan SC masih cukup wajar, tetapi dengan meningkatnya jumlah SC di tahun 2016 menjadi $38 \%$ maka efisiensi biaya perlu dipikirkan oleh manajer rumah sakit. Perlu dianalisis lebih dalam langkah apa yang harus dilakukan pihak RS untuk menekan angka SC. Rumah Sakit XY juga perlu dicari peluang income generating dari unit-unit lain yang tidak terlalu terpengaruh tarif INA CBGs seperti pelayanan poliklinik penyakit dalam dan saraf.

\section{Kesimpulan dan Saran}

\section{Kesimpulan}

Clinical pathways SC Tanpa Penyulit dan penanganan bayi baru lahir sehat melalui SC Tanpa Penyulit telah tersusun untuk kemudian diimplementasikan dan dihitung unit cost nya. Hasil penghitungan unit cost menunjukkan adanya perbedaan antara biaya yang riil dikeluarkan dengan standar tarif INA CBG's. Tarif INA CBG's tidak dapat menutup pengeluaran RS dalam memberikan pelayanan SC Tanpa Penyulit. Kebijakan RS XY yang akan dilakukan yaitu meninjau kembali struktur tarif dengan meninjau kembali biaya dasar, meningkatkan peran tim kendali mutu dan kendali biaya, meningkatkan CoB, mengkaji upaya agar biaya SC tidak meningkat serta menggali peluang income generating dari unit-unit lain dalam rangka meningkatkan pendapatan rumah sakit.

\section{Daftar Pustaka}

Nguyen KT, et al. 2002. Impact of Health Insurance on Health Care Treatment and Cost ini Vietnam : A Health Capability Approach to Financial Protection. American Journal of Public Health. Augustus 102; 8; 1450-1463;

Pemerintah RI. 2004. Undang-Undang Republik Indonesia Nomor 40 Tahun 2004 tentang Sistem Jaminan Sosial Nasional;

Kementerian Kesehatan Republik Indonesia. 2013. Buku Pegangan Sosialisasi Jaminan Kesehatan Nasional (JKN) dalam Sistem Jaminan Kesehatan Nasional;

Pemerintah RI. 2013. Peraturan Presiden Nomor 12 Tahun 2013 tentang Jaminan Kesehatan;

Pemerintah RI. 2013. Peraturan Presiden Nomor 111 Tahun 2013 tentang Perubahan Atas Peraturan Presiden Nomor 12 Tahun 2013 tentang Jaminan Kesehatan;

RS XY, 2011. Profil RS XY Kudus; 2015.Rachmawati I. Perhitungan Biaya Murni Sectio Caesaria Kelas III Berdasarkan Clinical Pathway di RSIA Hermina Podomoro. Jurnal PERSI. 10; 
Trisnantoro L. 2004. Memahami Penggunaan Ilmu Ekonomi dalam Manajemen Rumah Sakit. Gadjah Mada University Press;

Aljunid SM. 2013. Introduction to The DRG System and The Need for A Computerized Processing Environment. Information Technology for Unive RS Xl Health Coverage (IT4UHC). Manila Philippines;

Aniza I, et al. 2011. Comparing Cost for Elective Lower Segment Caesarian Section Costing Using Top-Down and Activity Based Cositng Methods. Malaysian Journal of Public Health Medicine 11(1):36-46;

Aniza I. 2010. Role of Clinical Pathways in Casemix System. Modul 1: Introduction To Case-Mix. United Nation University-International Institute Global Health;

Baker JJ. 1998. Activity-Based Costing and ActivityBased Management for Health Care. An Aspen Publication;

Albright HW, et al. 2009. Using TDABC to Understand Cost Drivers in Health Care, The University of Texas MD Anderson Cancer Center;

Mukti, AG. 2007. Reformasi Sistem Pembiayaan Kesehatan di Indonesia dan Prospek ke Depan. Yogyakarta: Magister Kebijakan Pembiayaan dan Manajemen Asuransi/Jaminan Kesehatan Fakultas
Kedokteran Universitas Gadjah Mada;

Damayanti, T. Pribadi, F. 2009. Analisis Unit Cost Sectio Caesaria dengan Metode Activity Based Costing di Rumah Sakit Bhayangkara. Yogyakarta;

Sari, DR. 2014. Unit Cost Tindakan Sectio Caesarea Tanpa Penyulit di Instalasi Bedah Sentral dengan Metode Activity Based Costing Studi Kasus di Rumah Sakit PKU Muhammadiyah Yogyakarta (tesis). Yogyakarta: Program Studi Magister Manajemen Konsentrasi Manajemen Rumah Sakit Fakultas Kedokteran dan Ilmu Kesehatan Universitas Muhammadiyah;

Kemeterian Kesehatan RI. 2013. Peraturan Menteri Kesehatan RI Nomor 12 Tahun 2013 tentang Pola Tarif Badan Layanan Umum Rumah Sakit di Lingkungan Kementerian Kesehatan;

Kemeterian Kesehatan RI. 2014. Peraturan Menteri Kesehatan RI Nomor 59 Tahun 2014 tentang Standar Tarif Pelayanan Kesehatan dalam Penyelenggaraan Program Jaminan Kesehatan;

Kementerian Kesehatan RI. 2016. Peraturan Menteri Kesehatan RI Nomor 52 Tahun 2016 tentang Standar Tarif Pelayanan Kesehatan dalam Penyelenggaraan Program Jaminan Kesehatan;

Kementerian Kesehatan RI. 2016. Peraturan Menteri 